\title{
Mulheres, arte e poder: uma narrativa de contrapoder?
} Ana Gabriela Macedo

\begin{abstract}
Muito antes de Karen Finley ter espalhado chocolate nas suas nádegas, de Annie Sprinkle nos ter mostrado o seu cérvix, ou de Orlan ter iniciado as suas performances de cirurgia de reconstrução cosmética, respeitáveis senhoras da Inglaterra eduardina foram pioneiras de uma nova forma de arte híbrida, na qual o privado se tornava político, o político era performativo, e a performance era pública.
\end{abstract}

Leslie Hill

\section{O privado é político (The personal is political)}

O título deste texto contém uma evocação de um ensaio fundamental de Linda Nochlin de 1988', precisamente intitulado “Women, Art and Power" (reproduzido posteriormente em Visual Theory, volume editado em 1991 por Norman Bryson, Michael Ann Holly e Keith Moxey)2. Tal como a autora declara logo na abertura do texto, o seu objetivo é investigar as relações existentes entre essa tríade, "women, art and power" num conjunto de imagens visuais em que as mulheres são representadas envolvendo situações de poder, isto é, imagens que traduzem narrativas de poder ou, sintomaticamente, de ausência deste. Narrativas essas que significam:

operações do poder ao nível da ideologia, operações que se manifestam de um modo mais difuso, mais absoluto e contudo mais paradoxal e sútil, através do que chamaremos os discursos da diferença de gênero (...). A ideologia manifesta-se tanto através do que é silenciado - considerado impensável e irrepresentável - como através do que é articulado no objecto artístico. (Nochlin, 1991, p. 13)

\footnotetext{
${ }^{1}$ Este texto foi anteriormente publicado no volume 11/12 da revista Margens e Confluências, Um Olhar Contemporâneo sobre as Artes, intitulado "Mulheres artistas. Argumentos de gênero", à data dirigida por Maria José Laranjeiro, editado pela ESAP (Escola Superior Artística do Porto - Guimarães), em dezembro de 2006, (p. 22-35). Quero deixar aqui expresso o meu agradecimento aos editores atuais da revista, na pessoa do seu diretor interino, professor Paulo Leocádio Ribeiro, pela autorização de reedição do meu artigo.

${ }^{2}$ Ver Nochlin (1989) e Nochlin (1991, p. 13-46). Salvo referência em contrário, todas as traduções de citações neste texto são da minha responsabilidade.
} 
As situações que Nochlin investiga neste ensaio são assim, essencialmente, narrativas da invisibilidade da mulher, ou da sua passividade, do seu silêncio e da sua "fraqueza", a sua identificação com a natureza e o doméstico, a sua existência em função do "outro", isto é, enquanto objecto do olhar artístico e não como agente, e não como sujeito e criadora (de arte) - lugares aqueles tidos como óbvios e irrefutáveis, parte da "ordem natural e eterna das coisas" que, tal como Nochlin faz notar, constituem um "subtexto que identifica a maioria das imagens através das quais as mulheres são representadas" (id., p. 14). O estudo de Nochlin propõese assim evidenciar as marcas do poder patentes no discurso dominante no que diz respeito à representação da imbricada teia de relações entre o gênero e a ideologia dominante, para aí denunciar/ desmascarar o véu de invisibilidade e o discurso de (suposta) legitimação que reveste essas mesmas marcas do poder. Já que, invocando Foucault em A história da sexualidade (1978, p. 86), a autora afirma: "o poder é tolerado na medida em que oculta uma considerável parte de si próprio".

O meu objetivo neste texto consiste, porém, em retomar esta questão sob a perspectiva inversa, isto é, partindo desse conhecimento, dessa precisa denúncia, procurar evidenciar os traços do que chamo o agenciamento feminino nas narrativas visuais, ou, dito de outro modo, sublinhar a criação ou construção de narrativas de contrapoder no seio dos discursos iconográficos dominantes.

Vou começar por referir um exemplo que tem sido citado por várias historiadoras e críticas de história da arte, entre as quais a própria Linda Nochlin no ensaio a que me tenho referido, mas também, e particularmente, Lynda Nead (1992) em "Redrawing the Lines", um ensaio incluído no volume The Female Nude: Art, Obscenity and Sexuality, ou ainda, mais recentemente, Leslie Hill (2000) ${ }^{3}$, num artigo intitulado "Suffragettes Invented Performance Art", donde extraí a minha epígrafe deste texto. Refiro-me ao episódio de "The Damaged Venus", tal como ficou conhecida a famosa pintura de Diego Velázquez, "The Rokeby Venus" ("A Vênus do Espelho", 1647-51) ${ }^{4}$, exposta na National Gallery (ver figs. 1 e 2).

\footnotetext{
${ }^{3}$ Quero agradecer a Francesca Rayner por ter trazido este texto à minha atenção.

${ }^{4} \mathrm{O}$ traço que mais tem sido salientado em relação à Vénus de Velázquez é a sua ambiguidade e o seu ar "aparentemente inacabado", o facto do reflexo da sua face no espelho ser vago e difuso, pelo que a pintura é usualmente descrita como um "nu reclinado", mais um corpo erótico de mulher do que uma deusa, acentuando-se assim em toda a sua plena significação, a "irrepresentabilidade do feminino" (veja-se a discussão de Xavier Portús, (2006, p. 56-67).
} 


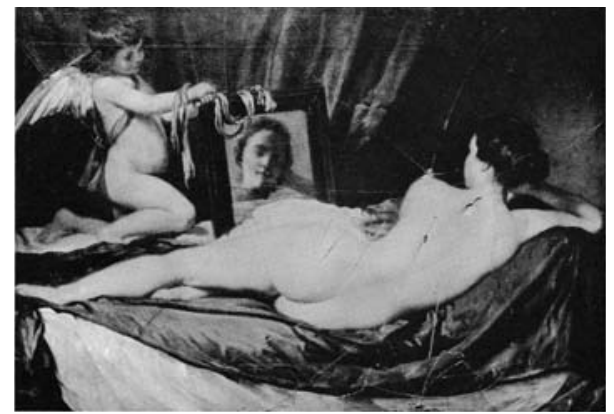

Fig. 1. Fotografia do ataque à Vénus de Velázquez, The Rokeby Venus, 1914.

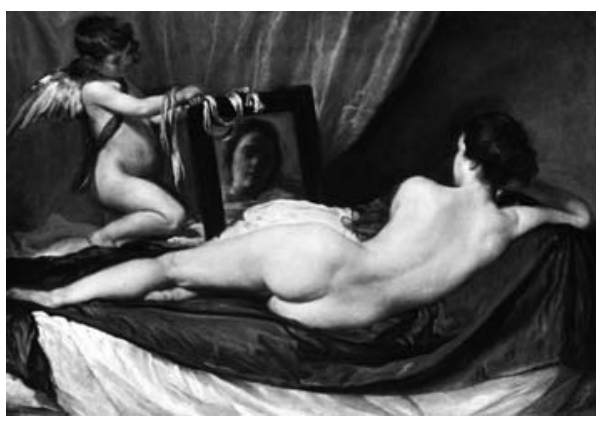

Fig. 2. A Vênus ao espelho, Diego Velázquez (1647-51).

O caso reporta-se ao incidente (político e estético) ocasionado pelo ataque da sufragista Mary Richardson, em 1914, à famosa pintura de Diego Velázquez, como parte dos violentos protestos das mulheres inglesas em luta pelo sufrágio, contra a violência sobre elas exercida pelo poder político na continuada negação do voto feminino, e mais ainda, concretamente contra o encarceramento da sua líder, mrs. Pankhurst, então na prisão de Holloway, em greve de fome. Tal como relata Leslie Hill no artigo citado, em 17 de Junho de 1911, 40 mil mulheres tinham já desfilado pelas ruas de Londres numa marcha gigantesca que ficou conhecida como "Women's Coronation Procession" (ver fig. 3), numa referência irônica à tradição inglesa dos desfiles reais da coroação (Hill, 2000, p. 155), criando um deslumbrante espectáculo de cor com as suas bandeiras de cores garridas, bordadas à mão, e outras ainda ostentando trajos históricos enquanto recriações alegóricas de heroínas femininas da história, tais como Joana d'Arc, criando assim um verdadeiro ambiente performativo. Assim, de idêntico modo, o violento gesto alegórico de Mary Richardson, que obviamente lhe valeu o encarceramento, deverá ser entendido tal como Lynda Nead (1992, p. 34-43) e Linda Nochlin (1991, p. 36-8) frisam, uma a instauração de uma performance antipatriarcal contra a imagem ideal da feminilidade, um poderoso e simultaneamente desesperado grito do privado no público, uma invasão retórica discursiva e performativa no status quo. E foram estas as palavras de Mary Richardson a propósito do seu ato: "Tentei destruir a imagem da mais bela mulher da história mitológica, como um protesto contra a destruição que o governo tem levado a cabo de mrs. Pankhurst, a mais bela personagem da história moderna" (apud Nead, 1992, p. 35). 


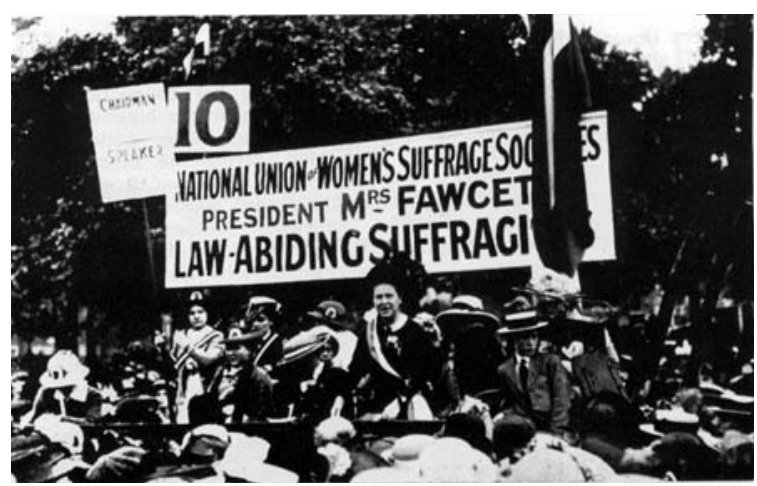

Fig. 3. Manifestação Sufragista, Londres, 1911.

É neste sentido que a epígrafe de Leslie Hall com que inicio este texto, sobre a arte, as mulheres e o poder, deve ser entendida no contexto da representação dialógica do corpo, simultaneamente como lugar de opressão e de resistência e, por outro lado, da continuada relevância da afirmação que o feminismo vem reivindicando ao longo de sucessivas gerações, de que "o privado é político".

\section{Corpo, identidade e a "política da localização"}

O corpo humano entra numa maquinaria de poder que o esquadrinha, o desarticula e o recompõe. Uma "anatomia política", que é também igualmente uma "mecânica do poder"... A disciplina fabrica assim corpos submissos e exercitados, corpos "dóceis".

Michel Foucault, Vigiar e punir

Começar, assim, não por um continente, por um país ou por uma casa, mas pela geografia mais próxima - o corpo. (...) A política da localização. Tentar ver, como mulher, a partir do centro.

Adrienne Rich

Num texto anterior ${ }^{5}$, debrucei-me já sobre o modo como a crítica feminista é devedora do pensamento de Michel Foucault no tocante ao modo pioneiro como ele demonstrou a excessiva discursivização existente em

\footnotetext{
5 "Re-presentações do corpo, Questões de Identidade e a Política da Localização", (Macedo e Grossegesse, 2003, p. 13-23). Num âmbito próximo, ver também o meu texto "Cartografias do feminino - Gênero, representação, identidade (2004, p. 29-42).
} 
torno do corpo e o modo como este foi "historicamente disciplinado", manipulado e adestrado, de modo a criar no sujeito uma autovigilância compulsiva e um autopoliciamento que o autor definiu como "um estado de permanente e consciente visibilidade, que assegura o funcionamento automático do poder" (Foucault, 1979, p. 201). Porém, tal como as teóricas Lois McNay (1992), Susan Bordo (1993), Moira Gatens (1996) ou Judith Butler (1993) fazem notar, reconhecendo embora o papel pioneiro de Foucault, a crítica feminista levou mais longe este questionamento ao chamar atenção para, citando McNay (1992, p. 33), a existência de uma "cegueira em relação às questões de gênero que sempre foram predominantes na teoria social". E McNay acrescenta:

Ao descrever o desenvolvimento de poder moderno como uma forma insidiosamente crescente de domínio e ao obscurecer todo o contexto social susceptível de organizar e regular o exercício do poder, Foucault apaga retroactivamente a natureza específica da subordinação feminina e sobrestima os efeitos normalizadores do poder disciplinatório na sociedade industrializada.

Moira Gatens (1996, p. 67) argumenta neste contexto que "não pode ser subestimado o impacto da teoria feminista nas ciências sociais pelo seu empenho em trazer o corpo para o foco da análise".

Por sua vez, Susan Bordo argumenta que se deve ao feminismo a prerrogativa de ter invertido e convertido a velha metáfora do "corpo político" (segundo a tradição de Platão, Aristóteles, Cícero, Séneca, Maquiavel, Hobbes, entre outros pensadores), numa nova metáfora - a "política do corpo":

Na velha metáfora do "corpo político", o estado da sociedade era imaginado como um corpo humano em que os diferentes órgãos e partes simbolizavam diferentes funções, necessidades e constituintes, forças, etc. (...) Para o feminismo o corpo é ele próprio uma entidade politicamente inscrita, sendo a sua fisiologia e morfologia moldada e marcada por práticas históricas de condicionamento e controle - desde o enfaixamento dos pés ao uso dos corpetes, à violação e ao espancamento, à heterossexualidade compulsiva, à esterilização forçada, à gravidez não desejada (...) ao tráfico explícito. (Bordo, 1993, p. 188-9)

Partimos assim neste texto do entendimento que a "re-conceitualização do corpo" feminino, ancorado numa geografia social e focando-o como o local privilegiado da construção e des-construção da identidade, não como um "ser", mas como uma "fronteira variável", uma superfície 
politicamente regulada" e um "campo de possibilidades interpretativas" (Butler, 1990) têm sido premissas fundamentais dos feminismo(s) contemporâneos, de Virgínia Woolf ou de Simone de Beauvoir a Adrienne Rich, de Rosi Braidotti a Griselda Pollock, de Judith Buler a Donna Haraway, para citar apenas alguns nomes. Tal como procurarei demonstrar, o corpo é hoje um foco central na arte feminina contemporânea.

Vou assim reportar-me agora, especificamente, ao campo das Poéticas Visuais, propondo-me analisar aqui duas estratégias concretas e contíguas de questionamento do corpo enquanto, "imagem psicologicamente construída que oferece a localização e a imagética dos processos do inconsciente, do desejo e da fantasia" (Pollock, 1996, p. 6). São estas as seguintes: estratégias de des-identificação e estratégias de empoderamento.

\section{Estratégias de des-identificação}

Tal como Griselda Pollock refere em Vision and Difference ${ }^{6}$, somos confrontados/as pela obra de muitas artistas contemporâneas, com recorrentes práticas de des-identificação e de ruptura, as quais, se bem que tenham já sido objeto de forte contestação nos anos 1970, têm vindo a constituir o paradigma central da arte pós-moderna. E citando Pollock:

As práticas de "des-identificação" reportam-se a estratégias que se destinam a impedir o espectador de se identificar com os mundos ficcionais ou ilusórios oferecidos pela arte, pela literatura ou pelo cinema, deste modo provocando uma ruptura na "dança da ideologia" de que somos reféns, em nome dos sistemas opressivos de classe, sexismo, heterossexismo compulsivo ou outros posicionamentos e classificações racistas. (Pollock, 1988, p. 158)

Segundo Pollock, o contributo fundamental do feminismo no contexto das artes terá sido a introdução da "outridade do paradigma da mulher (enquanto artista e crítica) como modelo da própria ruptura na poética e na política da representação: "o outro que finalmente reconciliaria estética e política" (id., 160).

Finalmente, e antes ainda de passar às imagens, poderemos acrescentar que a natureza das intervenções feministas na arte tornou visível a necessidade de repensar os modos de representação dominantes, através do questionamento teórico e do renovado estranhamento ideológico que

\footnotetext{
${ }^{6}$ Griselda Pollock faz uma excelente análise desta polêmica no capítulo "Screening the Seventies: sexuality and representation in feminist practice - a Brechtian perspective", in Vision and Difference (1988, p. 155-99).
} 
o feminismo tem instigado. Tal como Lynne Segal escreveu num artigo recente, e de modo algo paradoxal, "é tempo de exigir mais realismo em torno de nós" (Segal, 2000, p. 20), porém, acrescenta a autora, evitando a tentação de "colapsar" as diferentes vidas das mulheres "numa única narrativa linear". Esse é o desafio que o feminismo tem ainda de ser capaz de enfrentar.

Vejamos agora alguns exemplos:

\section{Barbara Kruger}

Barbara Kruger, nascida em Newark, New Jersey, em 1945, tem uma polifacetada obra e uma não menos polifacetada carreira, que iniciou muito jovem, na área do design, tendo sido ao longo dos anos fotógrafa, designer, crítica de arte, editora de revistas de arte, assim como de revistas de moda, acadêmica e conservadora de museu. Tal como Kate Linker (1996) escreve na introdução ao catálogo Love for sale, a sua obra demonstra claramente a intrusão do público no privado, recorrendo simultanea-mente a diferentes tipos de media. Seu tema predominante é o poder e seus jogos, estratégias, percursos e retórica; um poder que é anônimo, isto é, tem vários rostos, existe não centralizado num corpo único, mas antes difusamente espelhado numa rede de relações, aparelhos de Estado e instituições sociais (a família, a escola, a moral...), isto é, é discursivo, no sentido foucauldiano (Foucault, 1979). "Kruger é uma comentarista social, assim como uma agitadora política" (Linker, 1996, p. 12). Para Kruger as marcas do poder inscrevem-se no corpo, pelas imagens e poses estereotipadas; são figuras vazias, incorpóreas, através das quais o poder exerce livremente a sua autoridade, à semelhança dos "corpos dóceis" de Foucault ${ }^{7}$. Veja-se por exemplo a imagem "We have received orders not to move" (fig. 4), uma imagem que mostra uma mulher em pose de submissa imobilidade, espetada numa parede por alfinetes, numa evocação de diferentes discursos repressivos cuja função social poderá ser lida como "pôr a mulher no seu lugar" (id., p. 27-8). A sua obra é feita de poses e slogans facilmente reconhecíveis, que funcionam em relação ao observador através de um efeito duplo: de fascínio - pela imagem reconhecida, e de estranhamento - em relação à nova imagem/mensagem descodificada, ou "desmembrada" e

\footnotetext{
${ }^{7}$ Sobre o contributo do pensamento de Michel Foucault, as suas teorias sobre a disciplina, o poder e a fabricação dos "corpos dóceis", em articulação com a conceitualização feminista do corpo e a análise da subordinação social da mulher ver Lois McNay (1992) e Susan Bordo (1993). No artigo "Herstories: new cartographies of the feminine and the 'politics of location'" (Macedo, 2004), desenvolvi igualmente esta questão.
} 
reconfigurada enquanto campo semiótico ${ }^{8}$. O estereótipo é assim interceptado, a gratificação que a imagem provoca suspensa, e impedida assim a identificação passiva do observador com a mesma. Aproximamo-nos assim da prática de "des-identificação" referida anteriormente por Pollock. Veja-se igualmente a imagem "Use only as directed" (fig. 5).

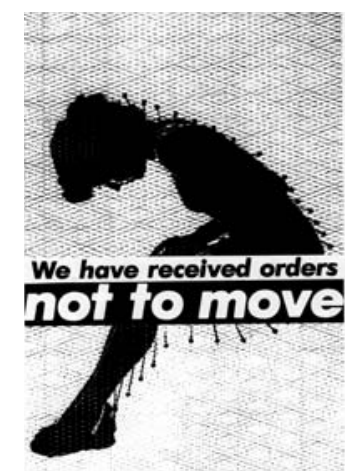

Fig. 4. Barbara Kruger, Untitled, 1982.

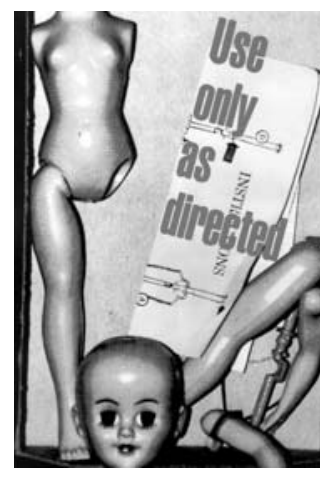

Fig. 5. Barbara Kruger, Untitled, 1988.

Inevitavelmente, a obra de Kruger está ligada ao pós-modernismo, enquanto condição histórica de pertença e não mera adoção fortuita de um estilo, ou de uma moda. Ela define uma estratégia assumida de ação, um posicionamento social e político, fruto de uma ampla teorização crítica. Veja-se a sua retórica visual da montagem, a colagem, a hibridização de estilos, textos e gêneros, o conceito do simulacro, a não hierarquização de registos e formas de discurso, o uso do palimpsesto e da sobreposição de texto e imagem, a intertextualidade estruturante do discurso 9 . Contudo, e tal como Craig Owens faz notar, a ênfase da obra de Kruger é sempre focalizada no gênero, se bem que não de um modo redutor e reificado, mas antes assinalando que masculino e feminino não são categorias fixas e estáveis (Owens, 1983, p. 77).

Finalmente, e de novo citando Kate Linker, o foco da obra de Kruger não é "o sujeito criativo da produção", à maneira modernista, mas antes

\footnotetext{
${ }^{8}$ Segundo Craig Owens (1983b, p. 7), citado neste texto por Kate Linker, o estereótipo é usado por Kruger como uma código, uma convenção: "o corpo é desmontado como um locus de prática e remontado como uma série descontínua de gestos e posturas, isto é, como um campo semiótico". A relação entre Kruger e Foucault é assinalada por Norman (1983). ${ }^{9}$ Analiso esta questão com mais detalhe em "A retórica da imagem fotográfica e a pós-modernidade: liminaridade, cumplicidade e crítica" (Macedo, 2000) e em "Poéticas Visuais e Reconfigurações do Corpo", (Macedo, 2005, p. 36-48).
} 
o questionamento pós-moderno do próprio processo de "produção do sujeito", isto é, o modo como as identidades são construídas pelas representações sociais, e, ainda, as estratégias através das quais essas mesmas representações "legislam, definem, exercem o poder" (Linker, 1996, p. 12). Assim, Kruger cria as suas próprias imagens através da reprodução e apropriação de outras imagens, globalmente do discurso dos media, da televisão, do cinema, da publicidade, de situações estereotipadas do quotidiano, anexando-lhes o discurso, esvaziando-o, esvaziando-lhe o sentido, metamorfoseando-lhe a retórica. Cria assim um discurso liminar que, ostensivamente, se alimenta de outros discursos e de distintas artes, escapando a classificações definidas de categorias de gêneros e campos semânticos. As tensões entre teoria, política e arte são expostas, do mesmo modo que os limites entre texto e imagem são explorados até ao limite. Poderemos assim dizer que, através de distintas "práticas de des-identificação", Kruger encena - irónica e performativamente - nos seus textos visuais a ruptura da identidade do sujeito no contexto da pós-modernidade, produzindo simultaneamente um discurso crítico de "resistência ou oposicional" (Hutcheon, 1988a e Huyssen, 1986), ou uma contradicção.

\section{Estratégias de empoderamento}

Os corpos articulam discursos, sem necessariamente falarem, porque são codificados com e como signos. Articulam códigos sociais. Tornamse intertextualizados, narrativizados; simultaneamente incarnam códigos sociais, leis, normas e ideais. Se os corpos são atravessados e infiltrados por saberes, significações e poder, eles podem igualmente, em determinadas circunstâncias, tornar-se polos de luta e resistência, inscrevendo-se ativamente em práticas sociais.

Elizabeth Grosz, Space, Time and Perversion

O questionamento do corpo no âmbito do feminismo tem sido inseparável da problematização da identidade do sujeito, conceito este que, tal como Stuart Hall faz notar, sofreu, nos últimos anos, "uma verdadeira explosão discursiva" no âmbito de uma imensa variedade de áreas disciplinares, todas elas, e cada uma a seu modo, empenhadas na desconstrução crítica de uma noção de identidade integral, originária e unifica$\mathrm{da}^{\prime \prime}$. Algumas das suas mais audaciosas premissas constituintes da crítica antiessencialista a concepções étnicas, raciais e nacionais de identidade, ainda segundo Hall, articulam precisamente os conceitos de "identidade cultural" e de "política da localização". 
Neste contexto se inscreve a necessidade de repensar as políticas da representação segundo o redesenhar dos limites do corpo enquanto signo, constructo, e foco potencial de resistência, implicando a descoberta de novas cartografias do feminino, tema que se tem vindo a manifestar fulcral na obra de muitas artistas plásticas contemporâneas, pintoras, fotógrafas, escultoras. Veja-se, a título de exemplo, a imagem da pintora britânica Jenny Saville, "Plan" (1993). Poderemos assim falar da prática feminista, num mundo em crescente globalização, nomeadamente no âmbito da cultura visual, como um imperativo da construção de uma "geopolítica da identidade", numa formulação de Susan Stanford Friedman, no eixo da qual é crucial o conceito de diferença, não de uma forma fetichizada ou reificada, mas antes permanentemente abraçando a contradição, a deslocação e a mudança. Tal como afirma Friedman: "Partindo de um enfoque inicial no silêncio e na invisibilidade, o feminismo transportou o seu questionamento para a localização - a geopolítica da identidade no seio de distintos espaços comuns do ser e do devir". O corpo deixa aqui de ser uma ficção ou uma entidade imaterial, para se transformar numa verdadeira "localização" que não necessita ser transcendida, mas antes, e permanentemente, reclamada.

\section{Paula Rego}

Centrando-nos agora ao agenciamento do feminino na arte como uma estratégia de empoderamento (empowerment), não já apenas como uma denúncia e contestação do papel passivo do sujeito feminino, mas agora também como afirmação de uma voz e uma centralidade nas práticas sociais e estéticas, vou referir dois exemplos de artistas portuguesas contemporâneas.

Paula Rego dispensa apresentações, limitar-me-ei aqui a citar uma afirmação sua numa entrevista no contexto de uma exposição realizada na Inglaterra que reuniu artistas de distintas gerações, From the Interior - Female Perspectives on Figuration (1997-98). Questionada sobre a sua experiência enquanto artista mulher, Rego respondeu:

As minhas pinturas são pinturas feitas por uma artista mulher. As histórias que eu conto são histórias que as mulheres contam. O que é isso de uma arte sem gênero? Uma arte neutra? Isso não faz sentido, pois não? (...) Há histórias à espera de serem contadas, e que nunca o foram antes. Têm a ver com tudo aquilo sobre o que jamais se ousou tocar - a experiência das mulheres (Rego, apud Roberts, 1997, p. 85).

Na obra de Rego sobressaem essencialmente a natureza do seu olhar 
feminino sobre o mundo e sobre a arte, codificado na apropriação imagética de um discurso transgressivo sobre o corpo, e um desassombrado questionamento das narrativas visuais tradicionais da história da arte, produzindo uma audaciosa revisão destas, sejam elas a representação da artista no seu estúdio; a inversão de papéis sexuais de artista e modelo; a denúncia do quietismo e da passividade e a exacerbação dos instintos e da sensualidade feminina; a exposição do abjecto e do grotesco por oposição aos estereótipos da fragilidade e ao culto do belo. Enfim, a subversão dos papéis tradicionais que o discurso homológico da ideologia e da moral dominantes impuseram à mulher, através da irrupção de uma despudorada e inquietante "female unruliness", numa expressão do antropólogo Victor Turner (1977, p. 41-2) ${ }^{10}$, que dialogicamente celebra a força e a energia primordiais do princípio feminino, e reclama uma "arte com gênero" (ver figs. 6 e 7).

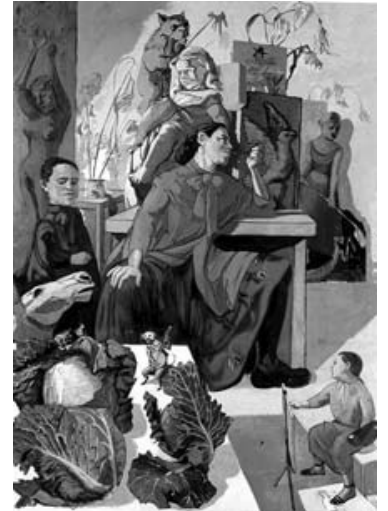

Fig. 6. Paula Rego, A artista no seu estúdio, 1993.

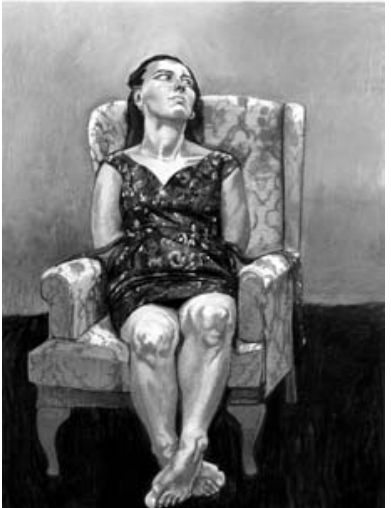

Fig. 7. Paula Rego, Quieta!, 1994

\section{JoAna Vasconcelos}

Finalmente, dois exemplos da obra de Joana Vasconcelos, uma jovem artista que vem sendo progressivamente reconhecida na cena artística nacional e internacional ${ }^{11}$. Por ocasião da Bienal de Veneza de 2005, a $51^{\text {a }}$

\footnotetext{
${ }^{10}$ Segundo Victor Turner, essa "desregramento feminino" "ameaça qualquer ordem social e parece ser mais ameaçador, mais que a ordem que parece rigorosa e segura" (Turner, 1977, p. 41-2).

${ }^{11}$ Recentemente uma escultura de Joana Vasconcelos foi selecionada para inaugurar simbolicamente o Museu Berardo instalado no CCB em Lisboa. Trata-se de uma obra, intitulada "Néctar", composta por dois elementos com 7 metros de altura, em inox, luz e vidro, numa referência irônica ao famoso ready-made de Duchamp, "Porte-Bouteilles".
} 
Bienal, a qual contou pela primeira vez na sua história com duas mulheres curadoras, as espanholas Rosa Martínez e Maria de Corral, J. Vasconcelos expôs uma escultura intitulada, A noiva, (ver figs. 8 e 9) exibindo um imenso candelabro de 5 metros de altura e 2 metros de largura feito com tampões femininos. O candelabro de J. Vasconcelos, que causou um grande impacto, foi escolhido para o átrio da exposição, a qual se realizou numa das áreas históricas da Bienal, o "Arsenale", como uma gigante metáfora prestando-se a grande possibilidade de leituras, da invasão da cultura popular na erudita, ao questionamento da ideologia masculina como a "luz dominante", parafraseando as curadoras da exposição. A proposta das curadoras foi reunir no prestigiado "Arsenale" uma seleção de obras de mulheres artistas de distintas gerações, desde a celebrada Louise Bourgeois, então com 93 anos (a mais jovem e a mais radical entre todas, segundo aquelas), a outras muito jovens e menos conhecidas. As norte-americanas Guerilla Girls (ver fig. 10) ${ }^{12}$ estiveram também presentes nesta Bienal de Veneza, através dos seus pôsters irônicos, questionando a barreira artificial entre alta cultura e cultura de massas e instaurando o seu sorriso anárquico e desconstrutor de mitos num dos mais "sagrados" espaços da arte.

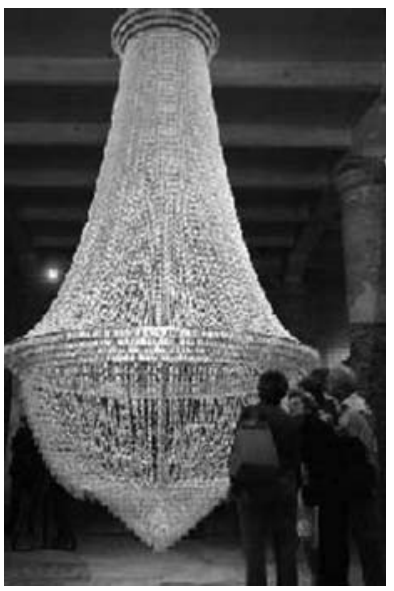

Fig. 8. Joana Vasconcelos, A noiva, 2005

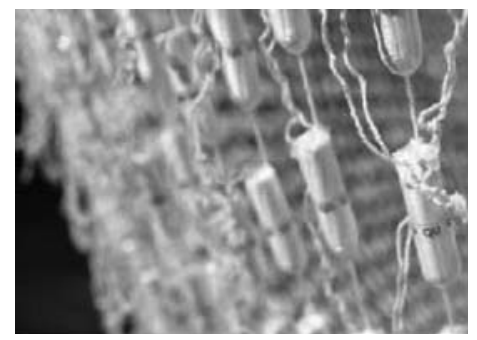

Fig. 9. Joana Vasconcelos, A noiva (detalhe), 2005.

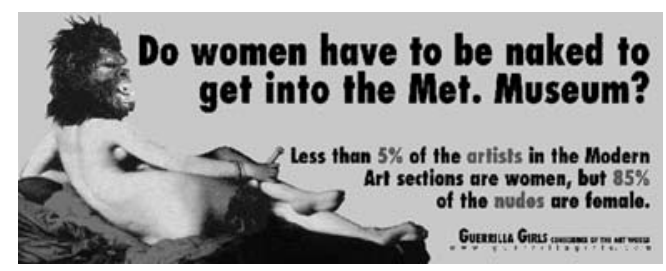

Fig. 10. Guerilla Girls, 1989.

${ }^{12}$ As Guerilla Girls expuseram a sua primeira versão deste pôster em 1989 no Metropolitan Museum de Nova York, onde, segundo afirmaram, menos de 5\% dos artistas exibidos eram mulheres, sendo que $85 \%$ dos nus eram de mulheres. Nesta sua nova versão daquele pôster reiteram que a situação, entretanto, pouco mudou. 
Termino também com o que espero seja entendido como um sorriso desconstrutor, neste caso uma fábula, isto é, uma passagem de Lewis Carroll, de Alice no país das maravilhas:

"E assim que eu acabara de alcançar a árvore mais alta da floresta", continuou o Pombo, elevando sua voz até lançar um grito estridente, "e estava pensando que estaria livre deles finalmente, eles têm que vir ziguezagueando pelos céus! Ah, Serpente!"

"Mas eu não sou uma serpente, eu vos digo! disse Alice. - Eu sou uma... Eu sou uma...

“Bem! O que é você?, disse o Pombo. Eu posso perceber que você está tentando inventar algo!"

"Eu... Eu sou uma garotinha", disse Alice, bastante insegura, já que recordava a quantidade de mudanças que tinha passado naquele dia.

“Uma história bem provável, realmente! disse o Pombo, em um tom do mais alto desprezo. "Eu já vi muitas garotinhas no meu tempo, mas nunca uma com tal pescoço! Não, não! Você é uma serpente, e isso não há como negar."

\section{Referências bibliográficas}

BORDO, Susan (1993). "Feminism, Foucault and the politics of the body". In: RAMAZANOGLU, Caroline (org.). Up Against Foucault: Exploration of some Tensions between Foucault and Feminism. Londres e Nova York: Routledge. BRAIDOTTI, Rosi (2000). "Between The No Longer and The Not Yet: Nomadic Variations On The Body". Bologna International Women's Conference. http:// 4thbo.women.it/plenary/braidotti.htm). Setembro.

BRONFEN, Elisabeth (1998). The Knotted Subject: Hysteria and its Discontents, Nova Jersey: Princeton University Press.

BRYSON, Norman (1993). Bodies That Matter: On the Discursive Limits of Sex. Londres e Nova York: Routledge.

22. Verão, n. 2, p. 183-93.

(1988). "Intertextuality and Visual Poetics". In: Visual Poetics. Style University Press.

(1983). Vision and Painting: The Logic of the Gaze. New Haven: Yale

BUTLER, Judith (1990). Gender Trouble: Feminism and the Subversion of Identity. Londre e Nova York: Routledge.

CARROLL, Lewis (1991). Alice in Wonderlan. Londres: Macmillan Children's Books.

ECKER, Gisela (Org.) 1982. Feminist Aesthetics. Londres: Virago.

EVANS, Jessica e HALL, Stuart (Orgs.) (1999). Visual Culture: The Reader. Londres/Nova Delhi: Thousand Oaks/Sage Publications. 
FOUCAULT, Michel (1978). The History of Sexuality. Nova York: Pantheon. v. 1. (1979). Discipline and Punish: The Birth of the Prison. Trad. Alan Sheridan. Nova York: Random House.

127. (1996). Vigiar e Punir: Nascimento da Prisão. Petrópolis: Vozes. p.

FRIEDMAN, Susan Stanford (1998). Mappings: Feminism and the Cultural Geographies of Encounter. Princeton: Princeton University Press.

GATENS, Moira (1996). Imaginary bodies: ethics, power, corporeality. Londres/Nova York: Routledge.

GROSZ, Elizabeth (1995). Space, Time and Perversion: Essays on the Politics of Bodies. Londres/Nova York: Routledge.

GREEENBLATT, Stephen (1997). Introduction to Interart Poetics. Essays on the Interrelations of the Arts and Media. Amsterdam: Rodopi.

HALL, Stuart (2000). “Who needs 'identity'?". In: GAY, Paul du; EVANS, Jessica; REDMAN, Peter (Orgs.). Identity: a Reader. Londres: Sage. p. 15.

HILL, Leslie (2000). "Suffragettes Invented Performance Art". In: GOODMAN, Lizbeth; GAY, Jane (Orgs.). The Routledge Reader in Politics and Performance.Londres e Nova York: Routledge. p. 150-6.

HUTCHEON, Linda (1988a). A Poetics of Postmodernism: History, Theory, Fiction. Londres: Routledge. (1988b). "Fringe Interference: Postmodern Border Tensions". In: Style 22. Verão, n. 2, p. 299-323.

HUYSSEN, Andreas (1986). After the Great Divide: Modernism, Mass Culture, Post-modernism. Bloomington: Indiana University Press.

JAMESON, Fredric (1984). "Postmodernism, or, the Cultural Logic of Late Capitalism". New Left Review. Jul-ago, p. 53-92.

KELLY, Jane (1997). "Picturing Women: Western Women Artists and Selfrepresentation 1970-95". In: LOYD, Fran (Org.). From the Interior: Female Perspectives on Figuration. Londres: Kingston University Press.

LINKER, Kate (1996). "Introdução ao catálogo Barbara Kruger". Love for sale. Nova York: Harry N. Abrams.

MACEDO, Ana Gabriela (2000). "A retórica da imagem fotográfica e a pósmodernidade: liminaridade, cumplicidade e crítica". In: BUESCU, Helena Carvalhão; DUARTE, João Ferreira (Orgs.). Entre Artes e Culturas, Act 2. Lisboa: Colibri. p.39-54.

(2001). "Through the looking-glass: Paula Rego's visual rhetoric, an 'aesthetics of danger'. In: Textual Practice. v. 15, n. 1, p. 67-85.

MACEDO, Ana Gabriela e GROSSEGESSE, Orlando (Orgs.) (2003). Re-presentações do Corpo/Re-presenting the Body. Braga: CEHUM.

MACEDO, Ana Gabriela (2004). "Cartografias do feminino - Género, representação, identidade. In: Revista Portuguesa de Psicanálise. Lisboa. v. 25, p. 2942.

(2000). “A retórica da imagem fotográfica e a pós-modernidade: li- 
minaridade, cumplicidade e crítica". In: BUESCU, Helena Carvalhão e DUARTE, João Ferreira (Orgs.). Entre Artes e Culturas, Act 2. Centro de Estudos Comparatistas. Lisboa: Colibri. p. 39-54.

(2004). "Herstories: new cartographies of the feminine and the 'politics of location'”. In: FORTUNATI, Vita; LAMARRA, Annamaria; FEDERICI, E. (Orgs.). The Controversial Women's Body: Images and Representations in Literature and Art. Bononia: Bononia University Press. p. 71-86.

(2005). "Poéticas Visuais e Reconfigurações do Corpo". In: Cadernos de literatura comparada. Porto: Afrontamento. n. 10-11, p. 36-48.

MARKS, Elaine e DE COURTIVRON, Isabelle (Orgs.) (1981). New French Feminisms: An Anthology. Nova York: Schocken Books/Massachusets University Press.

MCNAY, Lois (1992). Foucault and Feminism: Power, Gender and the Self, Cambridge: Polity Press.

NEAD, Lynda (1992) The Female Nude: Art, Obscenity and Sexuality. Londres/Nova York: Routledge.

NOCHLIN, Linda (1989). Women, Art and Power and other Essays. Londres: Thames and Hudson.

(1991). "Women, Art, and Power". In: BRYSON, Norman; HOLLY, Michael Ann; MOXEY, Keith Moxey (Orgs.). Visual Theory. Cambridge: Polity Press. p. 13-46.

OWENS, Craig (1983a). “The Discourse of Others: Feminists and Post-Modernism". In: FOSTER, Hal Foster (Org.). The Anti-Aesthetic. Port Townsend: Bay Press. p. 57-77.

Londres: ICA.

(1983b). “The Medusa Effect”. In: We won't play nature to your culture.

PARKER, Rozsika \& Pollock, Griselda (1981). Women, Art and Ideology. Londres: Pandora.

POLLOCK, Griselda (1988). Vision and Difference: Femininity, Feminism and the Histories of Art. Londres/Nova York: Routledge.

(Org.) (1996). Generations and Geographies in the Visual Arts. Londres/

Nova York: Routledge.

PORTÚS, Xavier (2006). "Nudes and Knights: A Context for Venus". In: Velázquez. London: National Gallery Company. p. 56-67.

PRICE, Janet e SHILDRICK, Margrit (Orgs.) (1999). Feminist Theory and the Body: A Reader. Edinburgh: Edinburgh University Press.

RILEY, Denise (1988). Am I That Name? Feminism and the Category of Women in History. Londres: Macmillan.

RICH, Adrienne (1987). Blood, Bread and Poetry: Selected Prose 1979-85, Londres: Virago.

RICH, Adrienne (2002). “Notas para uma política da localização”. Trad. Maria José Gomes. In: Género identidade e desejo: antologia crítica do feminismo contemporâneo. Lisboa: Cotovia. 
ROBERTS, Melanie (1997). “Eight British Artists - Cross Generational 'Talk'”. In: LLOYD, Fran (Org.). From the Interior: Female Perspectives on Figuration. Londres: Kingston University Press.

SEGAL, Lynne (1994). "Body Matters: Cultural Inscriptions". In: Straight Sex: The Politics of Pleasure. Londres: Virago.

(2000). "Feminist Futures". Keywords. v. 3, p. 10-21.

SULEIMAN, Susan Rubin (1986). The Female Body in Western Culture. Cambridge: Harvard University Press.

(1990). Subversive Intent: Gender, Politics and the Avant-garde, Cambridge: Harvard University Press.

TURNER, Victor (1977). "Frame, Flow and Reflection: Ritual and Drama as Public Liminality". In: BENAMOU, Michael e CARAMELLO, Charles (Orgs.). Performance in Postmodern Culture. v. 1. Madison: Coda Press.

Recebido em outubro de 2010.

Aprovado para publicação em dezembro de 2010.

\section{resumolabstract}

\section{Mulheres, arte e poder: uma narrativa de contrapoder?}

Ana Gabriela Macedo

Meu objetivo neste artigo é construir sobre o ensaio fundamental de Linda Nochlin, precisamente intitulado "Mulher, Arte e Poder" (1988), em que a autora investiga de forma convincente as relações dessa tríade. Em suas palavras, ela "desembaraça vários discursos sobre as relações de poder existentes nas diferenças de gênero simultaneamente - a superfície tanto quanto o substracto - o discurso da iconografia ou da narrativa". Proponho estender a análise de Nochlin, de alguma forma a mais, sem deturpar suas premissas, introduzindo uma mudança de foco no debate, da análise da representação de mulheres por artistas do sexo masculino, para o papel da mulher na arte contemporânea, ou seja, da mulher como objeto de representação para a mulher agente e sujeito da representação. Essa situação ganhou, efetivamente, um significado mais amplo a partir do final dos anos 1980. Sugiro, a partir da visualização de algumas imagens, que isso pode ser compreendido no contexto de produção de narrativas de empoderamento das mulheres ou, alternativamente, de criação de narrativas de contrapoder.

Palavras-chave: agenciamento feminino, discurso, contrapoder, arte feminista

\section{Women, art and power: a narrative of counter-power?}

Ana Gabriela Macedo

My aim in this paper is to build on a fundamental essay by Linda Nochlin precisely titled "Women, Art and Power" (1988), where the author convincingly investigates this triad while, in her own words, she "disentangles various discourses 
about power related to gender difference existing simultaneously with - as much surface as substractum - the master discourse of the iconography or narrative". I propose to extend Nochlin's analysis somehow further and, without twisting her premises, to introduce a shift of focus in this debate, from the analysis of the representation of women by male artists, to the role of the woman artist in contemporary art scene, i.e., from women as objects of representation, to women as agents and subjects of the representation. This situation, which has indeed gained wider significance since the late 80 s, I suggest (through the viewing of some examples), can be read within the context of the production of women's narratives of empowerment or, alternatively, as creating challenging narratives of counter-power.

Key words: female agency, discourse, counter-power, feminist art

Ana Gabriela Macedo - "Mulher, arte e poder: uma narrativa de contrapoder?". Estudos de Literatura Brasileira Contemporânea, n. 37. Brasília, janeiro-junho de 2011, p. 61-77. 